\title{
Inclusive universities: evidence from the Erasmus program
}

\author{
Luca De Benedictis ${ }^{1,2}$ and Silvia Leoni $i^{3^{*}}$ (D)
}

\author{
${ }^{*}$ Correspondence: \\ silvia.leoni@leicester.ac.uk \\ ${ }^{3}$ School of Business, \\ University of Leicester, \\ London Road 266, \\ Leicester LE2 1RQ, UK \\ Full list of author information \\ is available at the end of the \\ article
}

\begin{abstract}
The Erasmus Program is the main international mobility program in Europe and worldwide. Since its launch in 1987, it has been growing both in terms of participants and budget devoted to its activities. However, despite the possibility to obtain additional funding, the participation of students with special needs in the program remains extremely low. This work quantifies the participation of these students to Erasmus and explores the network of universities involved in their mobility, along the period 2008-2013. In addition, it proposes a novel index to measure the level of inclusiveness of universities welcoming international students with disabilities. Quantifying and analyzing this aspect could be the basis for better designing targeted policies and for widening the participation of students with impairments to international mobility.
\end{abstract}

Keywords: Erasmus, Disability, Special needs, Gender bias, Inclusiveness, Social network analysis

\section{Introduction}

The Erasmus Program (European Region Action Scheme for the Mobility of University Students) is the most famous example of student mobility in Europe and probably worldwide. Since its launch in 1987, the program has grown steadily, contributing to internationalize the higher education (HE) path of millions of students. In 2014, it transformed into Erasmus+ allowing also young people not in education, teaching, and administrative staff to take a period of mobility abroad for training, teaching, or carrying out activities within EU relevant projects. Its implementation is not limited to program countries in Europe, but it is extended to partner countries across the world, making it unique for reach and reputation. Its success is confirmed by the recent launch of the new Erasmus+ Program 2021-2027 with a budget of $€ 26.2$ billion, compared with $€ 14.7$ billion for 2014-2020 (European Commission 2021). The increased budget should allow for a more inclusive, more digital, and greener Erasmus.

However, its importance worldwide is not associated with an equal relevance in the scientific literature. Besides the internal reports produced by the EU institutions (European Commission 2015), literature has overlooked the participation to the Erasmus mobility and, as a consequence, little is known about its structure and evolution over time. Even less is known about the participation of students with special needs,

(c) The Author(s), 2021. Open Access This article is licensed under a Creative Commons Attribution 4.0 International License, which permits use, sharing, adaptation, distribution and reproduction in any medium or format, as long as you give appropriate credit to the original author(s) and the source, provide a link to the Creative Commons licence, and indicate if changes were made. The images or other third party material in this article are included in the article's Creative Commons licence, unless indicated otherwise in a credit line to the material. If material is not included in the article's Creative Commons licence and your intended use is not permitted by statutory regulation or exceeds the permitted use, you will need to obtain permission directly from the copyright holder. To view a copy of this licence, visit http:// creativecommons.org/licenses/by/4.0/. 
which would deserve major focus. Missed participation by students with disabilities due to barriers to mobility may lead to potential loss of individual and social benefits.

Erasmus' legal basis emphasizes the need to widen the program to people belonging to under-represented groups, or with special needs or fewer opportunities (European Parliament and Council of European Union 2013). In particular, the program commits to ensure the participation of individuals with physical, mental or healthrelated conditions by providing specific attention to guidance and accessibility, as well as additional funding via the Erasmus+ special needs support. When preparing for the Erasmus mobility, participants who wish to request this funding, need to indicate their extra costs following the application procedure established by each higher education institution. The additional grant is provided to offset specific difficulties faced by the participant, such as adapted accommodation, accompanying person, supportive equipment, adaption of learning material.

Nonetheless, Erasmus reports indicate extremely limited participation by students with special needs (European Commission 2015) and, contextually, the literature has not explored and quantified this phenomenon. This gap may be related to the scarcity and inaccuracy of statistical data available for international students with disabilities, as claimed by du Toit (2018).

This work intends to contribute to filling this gap by exploring i) the participation of students with special needs in Erasmus for study abroad and ii) the level of inclusiveness of participating universities. The ultimate objective is to increase awareness of potential issues related to this phenomenon and provide a quantitative basis for bodies in charge of related policies. We contribute to the literature in three ways.

First, we quantify the participation of students with disabilities in the Erasmus program for study reason only, with respect to students with special needs enrolled in HE in Europe, by exploring mobility by country and gender. Findings show that an extremely low share of Erasmus students is represented by students with disabilities and even a smaller portion of students with special needs in HE participate in the mobility. Almost every country participating in the program in 2013 showed a higher share of female students with disabilities leaving for mobility.

Second, adopting the tools of Social Network Analysis, we analyze the network of universities participating in the Erasmus mobility of students with special needs and compare it with the network of universities related to the overall participation of Erasmus students, explored in prior research (De Benedictis and Leoni 2020). We explore the topology of the network and verify whether the bias in favor of women which characterizes the overall network (Maiworm 2001; Bottcher et al. 2016; De Benedictis and Leoni 2020) is also present in the subnetwork of participants with special needs. This subnetwork appears much sparser than the overall network. The gender bias persists and increases along the period 2008-2013, contrary to the tendency found in the overall network. In the years of reference, an increasingly low share of participants studies a STEM discipline. Universities involved in the mobility of students with disabilities polarize in the role of senders or receivers, with the exception of universities located in countries' capital cities, which act as both senders and receivers. In particular, sending universities are located in Italy, Germany, and Eastern countries, 
whereas receiving institutions follow a South-West North-East axis, including Spain, France, UK, and Northern countries such as the Netherlands and Sweden.

Third, we propose a novel index to measure the level of inclusiveness of HE institutions participating in Erasmus. Only 13 universities hosted Erasmus students with special needs every year between 2008 and 2013 and among those some institutions outperform the average level of inclusiveness of their respective country, e.g. the University of Oslo and the Rijksuniversiteit Groningen, while others show a lower level of inclusiveness with respect to their country average, e.g. the University of Valencia and the Polytechnic University of Valencia.

The paper is organized as follows: the following section describes current research on the topic of international mobility of students with disabilities; the next section provides a quantification of the Erasmus mobility of students with special needs with respect to the number of students with disabilities in HE, and considers differences by gender; we then provide results from the analysis of the network of universities involved in the mobility of students with disabilities and finally we explore the level of inclusiveness of a group of universities, selected as the most inclusive for the period considered. We conclude with a summary of the main findings and a discussion on the limitations of our study and its potential extension in future research.

\section{Prior research}

\section{Benefits and barriers to international mobility}

Research showed that international mobility contributes to students' personal development (Keogh and Russel-Roberts 2009) through improved problem solving skill (Behrnd and Porzelt 2012), better knowledge of foreign languages (Otero and McCoshan 2006), more self-confidence (Braskamp et al. 2009), increased autonomy and flexibility (Kitsantas 2004; Papatsiba 2005), and future employability (Bryła 2015; Engel 2010; Parey and Waldinger 2010; d'Hombres and Schnepf 2021), as well as cultural awareness and the formation of individual identity (Oborune 2013; Langley and Breese 2005; Teichler and Jahr 2001). For the case of Italy, d'Hombres and Schnepf (2021) found that international mobility is linked with a higher probability to enroll in postgraduate studies. Improvement in soft skills and future career opportunities is proved also for students with disabilities (Hameister et al. 1999), for which better employability becomes particularly significant given the higher unemployment rate in their group (Eurostat: Disability statistics 2016). In addition, international mobility has shown to have specific advantages for disabled students. Shames and Alden (2005) found that after studying abroad, students with learning disabilities (LDs) and attention deficit hyperactivity disorder (ADHD) reported increased intellectual curiosity and more active engagement in the academic coursework and with peers, improved self-confidence, and improved knowledge of physical space and ability to orientate themselves, which can be difficult due to their disability.

Besides the potential benefits, prior research that has dealt with the international mobility of students with disabilities explored the barriers to participation and the best practices and policies that single HE institutions and countries shall adopt. Heirweg et al. (2020) conducted a study on 74 students with disabilities at the University of Bologna in Italy and found that they encountered financial, linguistic, and technical barriers 
(related to study programs and recognition of credits) in line with findings for barriers encountered by their non-disabled peers (Souto-Otero et al. 2013; Doyle et al. 2010). In addition, they met practical barriers concerning finding accommodations abroad and building a social life, and they claimed a lack of sufficient information about the support available at the host university, in line with findings by du Toit (2018) for the case of South African HE institutions. Johnstone and Edwards (2020) argue that efforts by HE institutions in favor of an increased level of accessibility are focused on providing appropriate accommodations to international students with disabilities but they are still at the beginning of including an accessibility culture into the design of study programs.

\section{The Erasmus mobility as a network}

Whereas current research has adopted qualitative methods, our approach is quantitative and relies on social network analysis to highlight the structure of students' flows. The network approach is not new to the study of international student mobility (Shields 2013) and Erasmus in particular (Restaino et al. 2020; Breznik and Skrbinjek 2020; Breznik 2017; Breznik and Djaković 2016; Derzsi et al. 2011; Breznik and Ragozini 2015). Prior research mostly conducted analysis at country level rather than university level, with the exception of De Benedictis and Leoni (2020) who focused on differences by gender and Derzsi et al. (2011) who studied the topology of the Erasmus student mobility network in 2003, revealing an exponential degree distribution and a small-word type random network with a giant component. Research has provided an overview of the most active sending and receiving countries (Breznik and Skrbinjek 2020; Restaino et al. 2020), by considering the network of all participants, without specific concern for students with disabilities. In particular, Breznik and Skrbinjek (2020) analyzed hubs and authorities at country level. They identified three different groups of countries: good senders and receivers, good senders only, and good receivers only. Restaino et al. (2020) further extended the analysis on hubs and authorities by adopting a blockmodeling approach on the network of countries involved in both the mobility for study and internship. They combined Erasmus data with Eurostat indicators and revealed the presence of a core-periphery structure in the mobility network, where key elements to attractiveness are economic benefits and investments in education.

Previous research relies on the same data source adopted in this work, however, in addition to our focus on universities as the unit of analysis rather than countries, our work differs from previous research along two further dimensions. First, prior works considered the network of all participants, without specific concern for students with disabilities. Second, our study combines the focus on students with special needs with an analysis by gender and by fields of study, grouped in STEM and non-STEM disciplines. Evidence from this study represents a novel contribution as adds two new dimensions to the study of Erasmus conducted so far.

On the one hand, social network analysis has not been employed to study the international mobility of disabled students, but on the other hand, it is difficult to find examples of its application to study the participation of students with disabilities in HE in general. Social network analysis has been adopted though to study friendship networks and peer acceptance of students with disabilities in primary and middle school, with results with 
limited external validity and generalizability (Mamas et al. 2020a, b; de Boer et al. 2013; Farmer et al. 1999).

\section{Erasmus for all?}

To quantify the participation of students with disabilities to Erasmus we rely on freely accessible data available at the EU open data portal. Notwithstanding Erasmus' long history, they consist of a limited number of datasets corresponding to different academic years and containing information for each participant to the mobility. We limit our analysis to the 6 years between 2008 and 2013, for a homogeneous comparison with the network examined in De Benedictis and Leoni (2020) and we rely on data for 2008-2018 only for aggregate figures. The information provided includes the type of mobility (study or placement), the home country and the host country, the home university and the host university, the field of study, the participant's gender, and whether the participant received additional funding for special needs, coded as a binary variable or reporting the amount of extra funding, depending on the dataset. We limit our analysis to participants involved in student mobility and discard observations related to traineeships and staff mobility. We select participants who benefited from the additional special need financial support, thus observations that report a "yes" or a value different than zero for the variable "special needs". This information may not exactly correspond to the number of students with disabilities involved in the mobility as it depends on self-disclosure of one's health condition and on the request for the extra grant (Bound et al. 2001), but we assume that it can be considered a good proxy for the number of disabled students involved, given the personal and national socio-demographic factors that can influence the individual propensity to apply to special needs funding.

When announcing the next Erasmus program in 2011, the full name of the program was "Erasmus for all" to recall its inclusive nature. Yet, despite its known benefits and the extra grant provided by the $\mathrm{EU}$, the participation of disabled students in the program remains low, signaling that additional funding does not compensate for the barriers that these students may encounter when undertaking the mobility.

In 2018 only $0.24 \%$ of Erasmus students received financial support for special needs. This low figure may reflect the low participation rates of students with special needs in HE and their high rate of dropout from education (Eurostat 2018). However, the number of participants with disabilities has more than doubled between 2008 and 2018 following the general trend in the overall participation and their rate of participation over the total number of participants has doubled with respect to its value in $2008(0.12 \%)$. This growth is displayed in Fig. 1 for the period 2008-2018 with bars for the absolute number of participants and with a yellow line indicating the percentage ratio between students with special needs and total students including disabled and non-disabled (\% SN/Tot); the figure also shows participation by gender and confirms that the known gender bias in favor of female Erasmus participants (De Benedictis and Leoni 2020) persists when considering only students with special needs. However, while the overall flows show a mild tendency towards reduction of this bias in later years, the flows of students with special needs show an increase in the ratio between female and male participants which is equal to 1.54 in 2008 and 1.95 in 2018. 


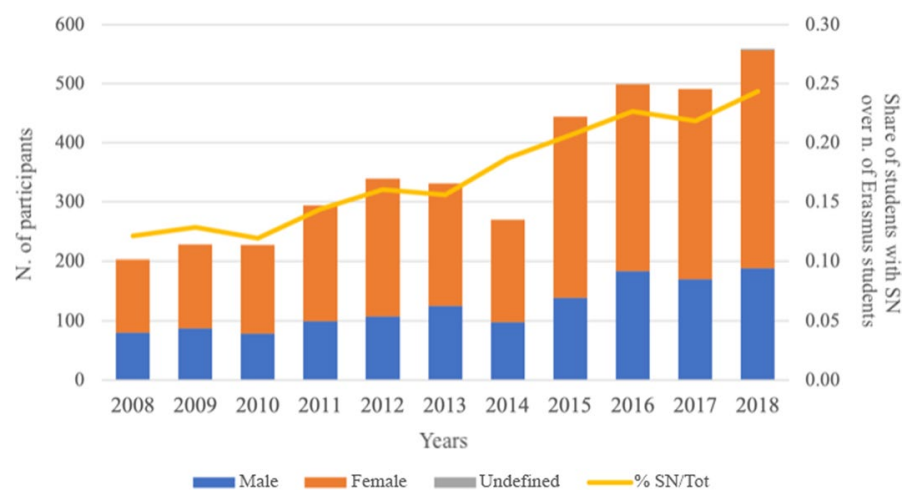

Fig. 1 Evolution of the participation of students with special needs to Erasmus. The bars indicate the number of participants for each year (to be read on the left vertical axis). The yellow line represents the share (\%) of students with special needs over the total number of Erasmus students (to be read on the right vertical axis)

To understand the order of magnitude of the participation of students with special needs to Erasmus with respect to those enrolled in HE, we attempted to collect data on students with disabilities in HE in the European countries by contacting the ministry of higher education of each country participating to the program. However, we received inadequate responses, with only a few countries keeping a systematic record of enrolled students with disabilities, hardly differentiating among the type of disability. Moreover, when present, the data collection process appears to have been established only in the latest years and the lack of homogeneity of data across country suggests that a country comparison would not be reliable. The lack of accurate information about students with disabilities in HE could depend on the protection of sensitive data, unwillingness to disclose personal details about health conditions, or insufficient awareness and communication among the players involved (de Boer et al. 2013). Therefore, we turned to information provided by Eurostudent, a project carried out by a consortium of organizations led by the German Centre for Higher Education Research and Science Studies (DZHW), with the aim to provide a crosscountry comparison of data on the social dimension of European higher education to support researchers and policy-makers. Information comes from the sixth round of the project to which 28 countries of the European Higher Education Area (EHEA) have contributed between 2016 and 2018, and it provides the share of students with impairments in HE on the basis of surveys submitted in the countries of interest. ${ }^{1}$ We apply the shares identified by the Eurostudent surveys on the number of students in HE provided by Eurostat for the year 2013 and in Fig. 2 we compare the share of outgoing Erasmus students by country over the total student population in HE for the case of students with disabilities only and for disabled and non-disabled students together. The share of students in HE leaving for mobility is quite low, it never reaches $1.5 \%$, with heterogeneous values across countries. On the other hand, the share of students with disabilities undertaking mobility is extremely lower, with

\footnotetext{
${ }^{1}$ Students with impairments include all students with long-standing health problems, and functional limitations (physical chronic disease, mental health problems, mobility impairments, sensory impairments (vision and hearing), and learning disabilities or other) regardless of the impact on their studies/ everyday life activities.
} 


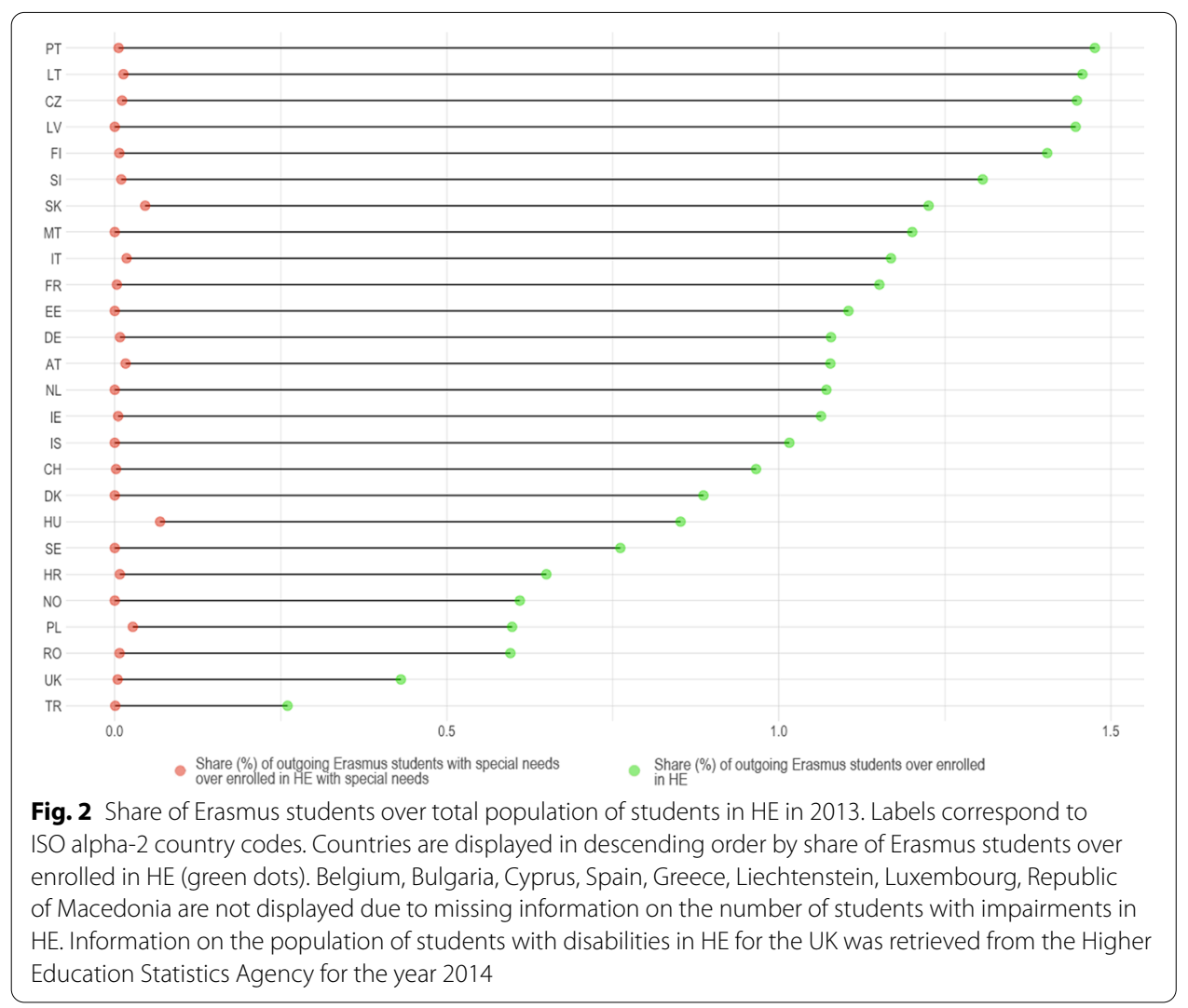

values close to zero. To provide an example, in Germany, only 51 students left for mobility out of approximately 643,000 estimated students with disabilities in HE; in France, 7 students left for mobility out of approximately 224,000 estimated students with disabilities in HE. Hungary and Slovakia report the highest shares but all countries show very small percentages. These values are displayed in Table 1 with a breakdown by gender. The share of women with disabilities participating in the mobility is larger in almost every country, with Hungary showing the highest value. In 2013 Hungary sent abroad 26 female students and 12 male students with disabilities. Exceptions are represented by Croatia, France, Italy, and Switzerland which sent abroad a higher share of male students with special needs. Countries such as Denmark, Estonia, Iceland, Latvia, Malta, Norway, Sweden, The Netherlands had no outgoing Erasmus students with disabilities in 2013. The limited availability of systematic and detailed data on the topic only allows speculating on the reasons why there is a prevalence of female outgoing Erasmus students. de Boer et al. (2013) showed that in school it is less likely for girls with disabilities to be accepted by their female peers when they show social problems. We hypothesize that if this characteristic persists in HE, it could represent a push factor for mobility in view of a potential greater acceptance abroad. In addition, there could be a gender difference in the ability to face barriers to mobility, and/or a need for a superior investment in international education to compensate for the foreseen gender gap in the labor market. 
Table 1 Share of outgoing Erasmus students with disabilities over male, female and overall students with disabilities in HE in 2013, by country and by gender

\begin{tabular}{|c|c|c|c|}
\hline Country & M \% & $F \%$ & Overall \% \\
\hline Austria & 0.0037 & 0.0264 & 0.0164 \\
\hline Croatia & 0.0094 & 0.0064 & 0.0077 \\
\hline Czech Republic & 0.0072 & 0.0140 & 0.0110 \\
\hline Denmark & 0.0000 & 0.0000 & 0.0000 \\
\hline Estonia & 0.0000 & 0.0000 & 0.0000 \\
\hline Finland & 0.0000 & 0.0116 & 0.0069 \\
\hline France & 0.0051 & 0.0016 & 0.0031 \\
\hline Germany & 0.0073 & 0.0086 & 0.0079 \\
\hline Hungary & 0.0487 & 0.0841 & 0.0684 \\
\hline Iceland & 0.0000 & 0.0000 & 0.0000 \\
\hline Ireland & 0.0000 & 0.0096 & 0.0051 \\
\hline Italy & 0.0245 & 0.0135 & 0.0178 \\
\hline Latvia & 0.0000 & 0.0000 & 0.0000 \\
\hline Lithuania & 0.0129 & 0.0133 & 0.0131 \\
\hline Malta & 0.0000 & 0.0000 & 0.0000 \\
\hline Norway & 0.0000 & 0.0000 & 0.0000 \\
\hline Poland & 0.0236 & 0.0292 & 0.0271 \\
\hline Portugal & 0.0052 & 0.0063 & 0.0058 \\
\hline Romania & 0.0048 & 0.0095 & 0.0072 \\
\hline Slovakia & 0.0404 & 0.0488 & 0.0457 \\
\hline Slovenia & 0.0000 & 0.0157 & 0.0099 \\
\hline Sweden & 0.0000 & 0.0000 & 0.0000 \\
\hline Switzerland & 0.0047 & 0.0000 & 0.0020 \\
\hline The Netherlands & 0.0000 & 0.0000 & 0.0000 \\
\hline Turkey & 0.0000 & 0.0016 & 0.0008 \\
\hline United Kingdom & 0.0043 & 0.0045 & 0.0044 \\
\hline
\end{tabular}

M stands for male; F stands for female. Belgium, Bulgaria, Cyprus, Spain, Greece, Liechtenstein, Luxembourg, Republic of Macedonia are not displayed due to missing information on the number of students with impairments in HE. Information on the population of students with disabilities in HE for the UK was retrieved from the Higher Education Statistics Agency for the year 2014

\section{A network of inclusive universities}

Following De Benedictis and Leoni (2020), we explore and visualize the network of universities taking part in the exchange program of students with disabilities. This represents a subnetwork of the network analyzed in De Benedictis and Leoni (2020). To allow for a comparison we maintain the focus on the years 2008 and 2013 and separate the analysis by gender.

The Erasmus Network at time $t, \mathcal{N}_{t}$ is a one-mode network defined by four sets of elements: $\mathcal{N}_{t}=(\mathcal{V}, \mathcal{L}, \mathcal{W}, \mathcal{O})$, where $\mathcal{V}$, identifies a set of nodes, represented by HE institutions; $\mathcal{L}$ is a set of directed arcs which identify the existence of an Erasmus exchange program between universities; $\mathcal{W}$ is the edge value function containing the weights corresponding to the flows of students involved in the mobility; $\mathcal{O}$ is the node value function containing information on universities, and on the country they belong. We first analyze the unweighted directed Erasmus network corresponding to a binary adjacency matrix $\mathcal{A}_{t}$, containing elements $a_{i j}=0$ if university $i \in \mathcal{V}$ does not link to university $j \in \mathcal{V}$ and $a_{i j}=1$ otherwise. Summary statistics are reported in Table 2 . The network appears to 
Table 2 Summary statistics_Erasmus network Special needs_2008 and 2013

\begin{tabular}{|c|c|c|c|c|c|c|}
\hline & \multicolumn{3}{|l|}{2008} & \multicolumn{3}{|l|}{2013} \\
\hline & All & M & $\mathrm{F}$ & All & M & $\mathrm{F}$ \\
\hline Active Universities & $\begin{array}{l}252 \\
{[2290]}\end{array}$ & 130 & 170 & $\begin{array}{l}388 \\
{[2658]}\end{array}$ & 198 & 277 \\
\hline Sending & 122 & 65 & 82 & 187 & 97 & 134 \\
\hline Receiving & 160 & 74 & 104 & 245 & 112 & 167 \\
\hline University partnerships & 199 & & & 324 & & \\
\hline Active connections & 202 & 80 & 122 & 328 & 125 & 203 \\
\hline Isolates & 649 & 771 & 731 & 513 & 703 & 624 \\
\hline Density & $\begin{array}{l}0.0002 \\
{[0.006]}\end{array}$ & 0.0001 & 0.0002 & $\begin{array}{l}0.0004 \\
{[0.008]}\end{array}$ & 0.0002 & 0.0003 \\
\hline Degree & 0.004 & 0.002 & 0.003 & 0.005 & 0.003 & 0.003 \\
\hline Out & 0.008 & 0.003 & 0.007 & 0.008 & 0.004 & 0.006 \\
\hline In & 0.004 & 0.003 & 0.003 & 0.005 & 0.002 & 0.004 \\
\hline Closeness & 0.00021 & 0.00001 & 0.00006 & 0.00045 & 0.00002 & 0.00012 \\
\hline Out & 0.00002 & 0 & 0.00001 & 0.00003 & 0.00001 & 0.00002 \\
\hline In & 0.000012 & 0 & 0.00001 & 0.00002 & 0 & 0.00001 \\
\hline Assortativity & -0.0194 & -0.016 & -0.0859 & 0.0813 & -0.0636 & 0.1001 \\
\hline Strength & 203 & 80 & 123 & 331 & 125 & 206 \\
\hline STEM & 39 & 21 & 18 & 45 & 22 & 23 \\
\hline non-STEM & 164 & 59 & 105 & 286 & 103 & 183 \\
\hline
\end{tabular}

See Wasserman and Faust (1994) for the definition of the statistics used. $M$ stands for male; $F$ stands for female. Degree stands for Degree centralization (standardized); Closeness stands for Closeness centralization (standardized); Act i ve connections includes student flows in different fields of study; the Assortat ivity score is $[-1,1]$. Values in squared brackets refer to the entire network of Erasmus student flows and are taken from (De Benedictis and Leoni 2020)

be much more restricted with respect to the network including also non-disabled students. It is made of 901 academic institutions with 252 active universities in 2008 (with 649 Isolates), out of the 2290 universities participating in the Erasmus program, and 388 in 2013 (and 513 Isolates, giving evidence to a low degree of persistence in the participation of universities in the network $)^{2}$, out of 2658 universities. The data on active universities shows relevant characteristics of the Erasmus network of students with disabilities: the prevalence for receiving rather than sending students in mobility. This brings up the existence of a cluster of inclusive universities, hosting students with disabilities in higher proportions. Comparing the two years under scrutiny, $\mathcal{L}_{2008}=199$ and $\mathcal{L}_{2013}=324$ indicates that 125 more partnerships were established between 2008 and 2013. Like the overall network, it is characterized by numerous isolated nodes whose number decreases along time, as its Dens ity increases. However, the network remains quite sparse, much more than the corresponding overall network in De Benedictis and Leoni (2020) (see the values of the Density in squared brackets), signaling that the probability to have a tie between two random nodes is just a little bit higher than zero. Degree centralization and Closeness centralization present values close to zero, signaling that the network is far from having a hierarchical structure. The level of homophily in the network increases over time with a modest disassortativity in 2008 changing

\footnotetext{
${ }^{2}$ Many universities are active senders or receivers only from time to time, given the very low number of students with a disability that take advantage of the Erasmus program.
} 
into a modest level of Assortativity in 2013, meaning that universities increasingly tend to connect with other universities showing similar characteristics in connectivity. However, the level of reciprocity, i.e. the likelihood of nodes to be mutually connected, is null. All this shows that the network is somehow randomly formed without any systematic attempt to coordinate an international university policy to favor the international mobility of HE students with disabilities.

Looking at differences by gender, in line with findings from Bottcher et al. (2016) and De Benedictis and Leoni (2020), the female Erasmus network of students with disabilities is more connected than the male network, with a ratio between $\mathcal{L}_{2008}^{F}$ and $\mathcal{L}_{2008}^{M}$ equal to 1.525 and between $\mathcal{L}_{2013}^{F}$ and $\mathcal{L}_{2013}^{M}$ equal to 1.624 . The bias in favor of women persists and increases over time, contrary to the mild tendency to a reduction shown by the overall network. The male network is characterized by a modest disassortativity in both years considered, whereas the female network aligns to the tendency towards an increased assortativity along time, showed by the whole network of Erasmus students.

We also explored the weighted version of the network, taking into account flows of students associated with each link, and computed the strength of the network as the sum of all weights, by gender and field of study aggregated in STEM and non-STEM disciplines. ${ }^{3}$. The overall strength of the network increases over time indicating that Erasmus has become more inclusive with increasing participation of students with disabilities, as shown in the previous section.

The small difference between University partnerships and Active connections indicates that sending university tend to send one single student with special needs (the rare exceptions are quantified by the difference between Active connections and Strength). Results displayed in Table 2 show an overall prevalence of mobility in non-STEM fields both for males and females. However, $26 \%$ of male participants study a STEM discipline in 2008 against $14 \%$ of female participants; the imbalance persists in 2013 with $17 \%$ of males and 11\% of females studying in STEM, revealing also an overall decreasing proportion of Erasmus students with disabilities in STEM disciplines.

The directed and weighted network is represented in Fig. 3. We exploited the information related to the cities where universities are located to extract geographical coordinates through Google Maps and combined the network visualization with the map of Europe. Figure 3 shows how the network becomes denser along the years considered, as reported in Table 2 and highlights the prevalence of female flows, colored in red, over male flows, in cyan. The figure also depicts the flows of mobile students in STEM disciplines with a dashed line, while the flows of students enrolled in non-STEM disciplines are represented by a solid line. Given the minority of Erasmus students in STEM subjects, the dashed lines are almost unnoticeable, especially for the year 2013 when the network is denser.

By keeping track of the geographical position of countries, Fig. 3 also gives evidence of intra-country heterogeneity between universities. In fact, the use of Network Analysis

\footnotetext{
${ }^{3}$ Fields are classified according to the ISCED-F 2013 classification. The STEM fields include Engineering, manufacturing and construction, ICTs and Natural sciences, mathematics and statistics. The remaining fields are classified as non-STEM.
} 
Table 3 Summary statistics_Erasmus network Special needs_2008 and 2013

\begin{tabular}{|c|c|c|c|c|c|c|}
\hline & \multicolumn{3}{|l|}{2008} & \multicolumn{3}{|l|}{2013} \\
\hline & All & M & $F$ & All & $M$ & $\mathbf{F}$ \\
\hline \multirow[t]{10}{*}{ Top- 5 sending universities } & POZ01 & WAR01 & POZ01 & KRA01 & BER01 & POZ01 \\
\hline & {$[7]$} & [3] & {$[6]$} & {$[8]$} & {$[4]$} & {$[6]$} \\
\hline & BUD01 & PAD01 & BER01 & POZ01 & ATH01 & WAR01 \\
\hline & {$[7]$} & {$[2]$} & {$[5]$} & {$[8]$} & {$[3]$} & {$[5]$} \\
\hline & WAR01 & POR02 & BUD01 & WAR01 & KRA01 & KRA01 \\
\hline & {$[6]$} & [2] & {$[5]$} & {$[7]$} & [3] & {$[5]$} \\
\hline & BER01 & PER01 & BRN05 & BUD03 & BRA02 & BUD03 \\
\hline & {$[6]$} & {$[2]$} & {$[4]$} & {$[7]$} & {$[3]$} & {$[5]$} \\
\hline & WRO01 & CAG01 & WRO01 & BUD20 & RZE02 & GDA02 \\
\hline & {$[6]$} & {$[2]$} & {$[4]$} & {$[6]$} & {$[3]$} & {$[4]$} \\
\hline \multirow[t]{10}{*}{ Top-5 receiving universities } & GRA01 & COR01 & MAD14 & BAR01 & MAN04 & BAR01 \\
\hline & {$[4]$} & {$[3]$} & {$[3]$} & {$[5]$} & {$[2]$} & {$[4]$} \\
\hline & PRA07 & GRA01 & MAD03 & SAN01 & LIN01 & GEN01 \\
\hline & {$[4]$} & [3] & [3] & {$[4]$} & [2] & [3] \\
\hline & CORO1 & LEI01 & GOT01 & BER01 & AMSO2 & SAN01 \\
\hline & [3] & [2] & [3] & {$[4]$} & {$[2]$} & [3] \\
\hline & MAD14 & PRA07 & DUB04 & GEN01 & ANG01 & LEU01 \\
\hline & [3] & {$[2]$} & [3] & [3] & {$[2]$} & [3] \\
\hline & VAL01 & PRE01 & PON01 & LUN01 & HUE01 & BER01 \\
\hline & [3] & {$[1]$} & {$[2]$} & [3] & {$[2]$} & [3] \\
\hline
\end{tabular}

Erasmus university codes have been shortened for visualization purpose: AMS02 = NL AMSTERD02; ANG01 = F ANGERS01; $\mathrm{ATH} 01=\mathrm{G}$ ATHINE01; BAR01 = E BARCEL01; BER01= D BERLIN01; BRA02 = SK BRATISL02; BRN05 = CZ BRNO05; BUD01= HU BUDAPES01; BUD03 = HU BUDAPES03; BUD20 = HU BUDAPES20; CAG01 = ICAGLIAR01; COR01 = IRLCORK01; DUB04 $=$ IRLDUBLIN04; GDA02 = PL GDANSK02; GEN01 = CH GENEVE01; GOT01 = D GOTTING01; GRA01 = E GRANADA01; HUE01 = E HUELVA01; KRA01 = PL KRAKOW01; LEI01 = D LEIPZIG01; LEU01 = B LEUVEN01; LIN01 = S LINKOPI01; LUN01 $=\mathrm{S}$ LUND01; $\mathrm{MAD03}=\mathrm{E}$ MADRID03; MAD14 = E MADRID14; MAN04 = UK MANCHES04; PAD01 = IPADOVA01; PER01 = I PERGUGIA01; PON01 = UK PONTYPRO01; $\mathrm{POR} 02=\mathrm{P}$ PORTO02; $\mathrm{POZ01}=\mathrm{PL}$ POZNAN01; PRA07 = CZ PRAHA07; PRE01 = UK PRESTON01; RZE02 = PL RZESZOW02; SAN01 = E SANTIAG01; VAL01 = E VALENCI01; WAR01 = PL WARSZAW01;WRO01 = PL WROCLAW01. Squared parentheses contain the degree value

not only allows us to give evidence to the structural characteristics of the international flows of Erasmus students with disabilities and, in this case, to acquire information on the connections among universities. It also allows identifying the institutions that play a central role in the mobility program. This information can be acquired through different centrality measures. For instance, the hub and authorities centrality scores (Kleinberg 1999) could help identify sending universities (hubs) and receiving universities (authorities), however, the computation of these scores loses relevance in such a sparse network. Thus, we rely on the indegree and outdegree centrality measures to identify the top sending and receiving universities, which are displayed in Table 3 . These centrality measures contribute to highlight the difference in connectivity between the female and male graph and its persistence over time. The nodes with the highest outdegree centrality in 2008 are the Adam Mickiewicz University of Poznan in Poland (PL POZNAN01) and the Eötvös Loránd University in Budapest (HU BUDAPES01), Hungary, with $\operatorname{deg}\left(v_{\max }\right)$ equal to 7, and in 2013 two Polish institutions, the Jagiellonian University in Krakow (PL KRAKOW01) and the Adam Mickiewicz University of Poznan, with $\operatorname{deg}\left(v_{\max }\right)$ equal to 8. In the network including non-disabled students (De Benedictis and Leoni 2020), the centrality measures showed that the top sending universities roughly coincided with the 

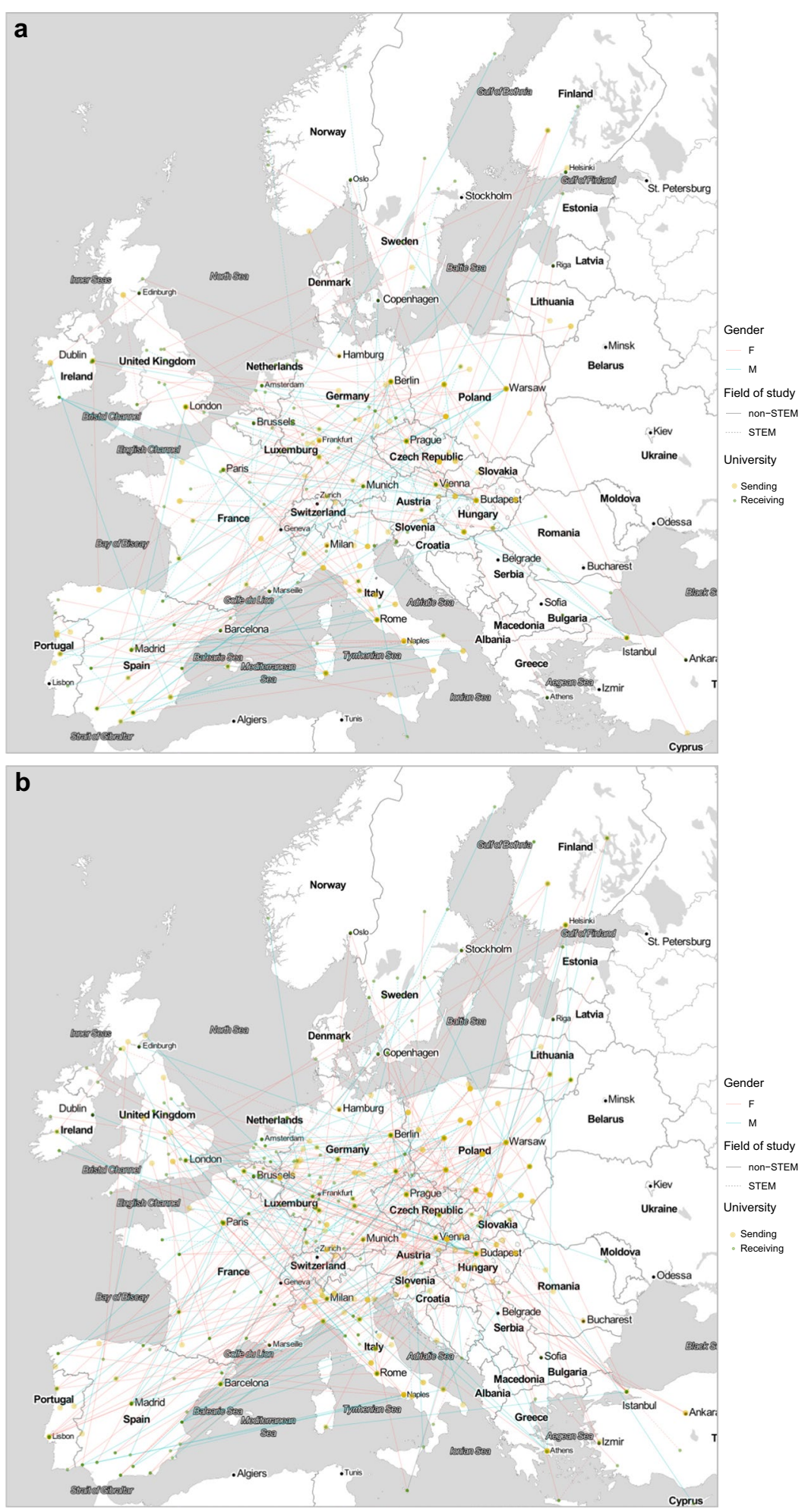

Fig. 3 The network of Erasmus universities sending and receiving students with special needs in 2008 (a) and 2013 (b). Yellow (Green) dots represent sending (receiving) universities. Red (Cyan) links represent flows of female (male) Erasmus students. Continuous (dashed) links represent flows of students enrolled in non-STEM (STEM) fields 
top receiving ones. However, this is not the case in the network of students with disabilities: centrality measures show a polarization of universities, with different geography for sending and receiving universities. The University of Granada (E GRANADA01) in Spain and the Charles University in Prague (CZ PRAHA07), Czech Republic, are the top receiving universities in 2008 with $\operatorname{deg}\left(v_{\max }\right)$ equal to 4, whereas the University of Barcelona (E BARCELO01) is the top receiving in $2013\left(\operatorname{deg}\left(v_{\max }\right)=5\right)$. This polarization becomes more evident in Figs. 3 and 4.

Figure 3 highlights the role of universities as senders and/or receivers respectively in yellow and green. The maps reveal that the universities located in countries capital cities tend to be simultaneously sending and receiving universities, while the rest of institutions mostly exclusively send or host international students, following a precise trajectory, as highlighted by the contour lines in Fig. 4, where the polarization is even more visible. Sending universities (yellow dots) are concentrated (yellow contour) in Italy, Germany, and Eastern countries, whereas receiving institutions (green dots) follow a South-West North-East trajectory (green contour), including Spain, the UK, and Northern European countries. This polarization and trajectory get reinforced in 2013. Universities that do not participate in the network of Erasmus students with disabilities are visualized as gray dots and are ten times more numerous.

The green contour in Fig. 4 gives a first indication of the geography of inclusive universities. In the next section we are going to explore the heterogeneity of it.

\section{Measuring inclusiveness}

The indegree centrality measures offer a good indication of which universities are the most inclusive in the two reference years, however, they provide an absolute figure, regardless of the general trend of the country they belong to and the total number of incoming Erasmus students. If indegree and instrength offer a quantification of the willingness and the readiness to welcome and host in an comfortable way foreign students with disabilities, they are however absolute measures.

In order to obtain a relative measure, we consider the weighted network of universities and propose an index of inclusiveness built as follows:

$$
I^{B}=\frac{I+1}{I-1} \quad \text { where } \quad I=\text { instrength }{ }_{u} \times \frac{i_{c}}{i_{u}} \equiv \frac{i_{s n, u}}{i_{s n, c}} \times \frac{i_{c}}{i_{u}},
$$

where $i_{s n, u}$ and $i_{s n, c}$ are respectively the number of incoming students with special needs by university and by country, whereas $i_{u}$ and $i_{c}$ are respectively the number of incoming students, disabled and non-disabled, by university and by country. The superscript $B$ stands for bounded, as the index is a symmetric transformation of $I$ to obtain a value ranging between $[-1,1]$. The index represents a measure for the distance between the ratio of incoming students with disabilities at university level and at country level and quantifies how far the university trend is from the country average. Values equal to zero indicate a perfect alignment of institutions to their country; positive (negative) values indicate a positive (negative) misalignment with respect to their country, i.e. a higher (lower) level of inclusiveness with regard to the average of their country.

To take into account variations along time the index is averaged across 2008, 2009, and 2010 to obtain a mean value for the beginning of the time span, and across 2011, 2012, 

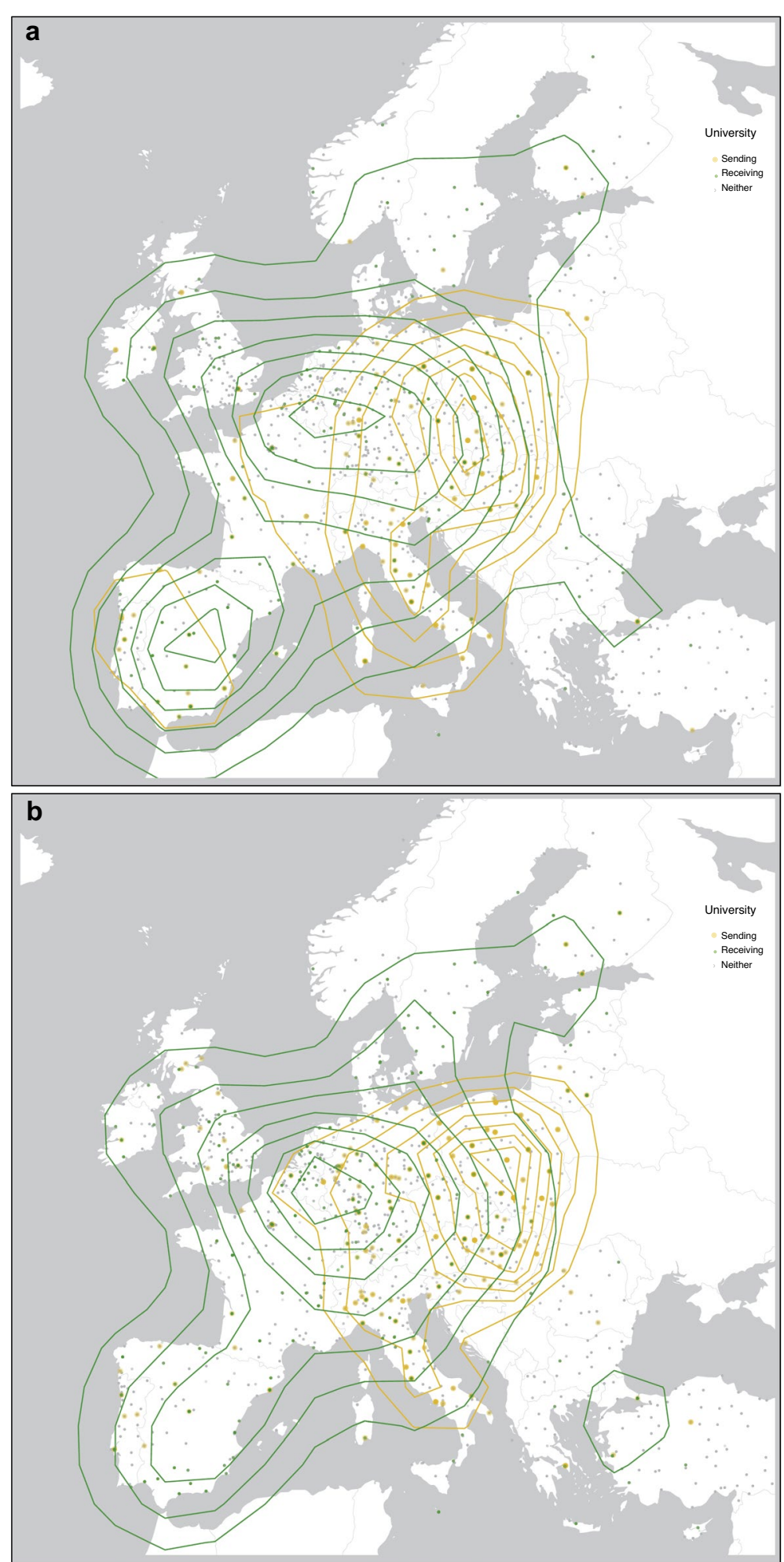

Fig. 4 The polarization of sending and receiving universities in 2008 (a) and 2013 (b). Yellow dots represent sending universities. Green dots represent receiving universities. Grey dots represent universities that neither send nor receive Erasmus students with special needs. The yellow contour visualizes the density of sending universities. The green contour visualizes the density of receiving universities 


\section{8}

2013

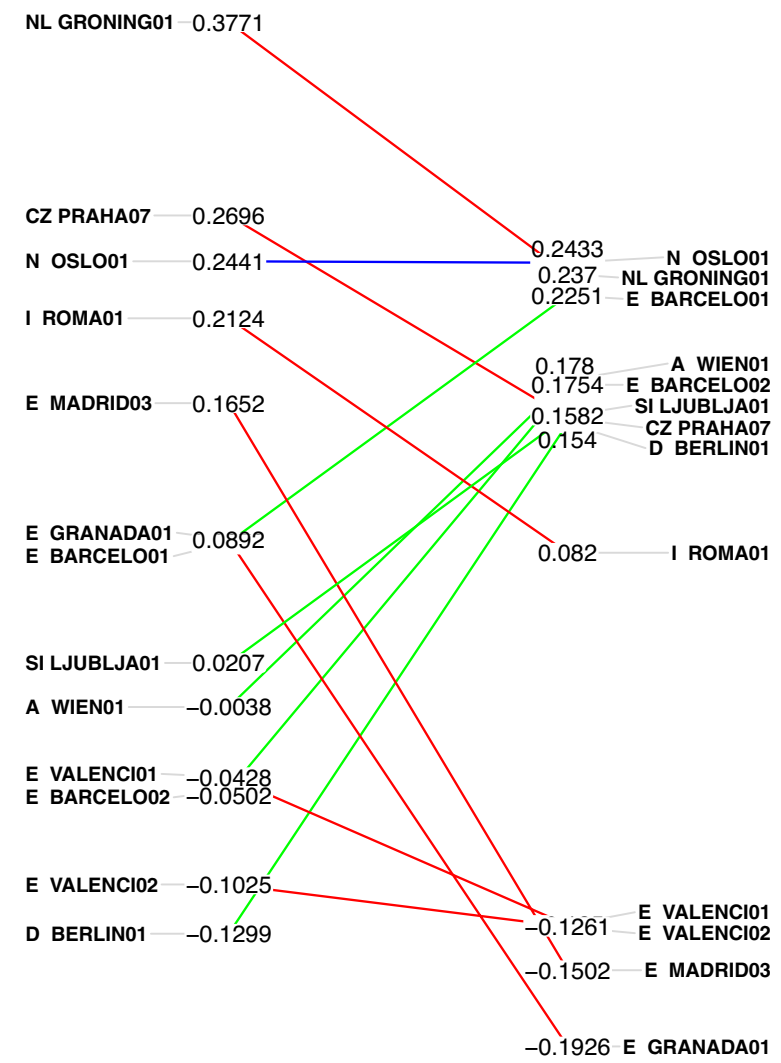

Fig. 5 Average index of inclusiveness at the beginning and at the end of the period 2008-2013. Different line colors indicate different behaviors along time. Red (green) lines highlight a decrease (increase) in the level of inclusiveness; the blue line signals that the level of inclusiveness remained unchanged over time

and 2013 to compute an average value for the end of the period considered. We only consider the universities receiving students with special needs in each of the six years of reference, that is $13 \mathrm{HE}$ institutions. A very small number of universities was able to continuously welcome international students with special needs. The measures obtained are displayed in the Tufte's slopegraph in Fig. 5.

Values tend to be close to zero, meaning that the level of inclusiveness of the 13 universities examined does not differ much from the respective country average. At the beginning of the period, the Rijksuniversiteit Groningen (NL GRONING01) is on average the most inclusive university according to our definition, while the Freie Universität Berlin (D BERLIN01) is the least inclusive among the group analyzed. At the end of the period, the University of Oslo and the University of Granada are on average the most and the least inclusive of the group of universities hosting foreign Erasmus students with disabilities.

Three different behaviors can be observed over time. First, the University of Oslo does not undergo any change and its value remains constant. Second, a group of universities worsens its level of inclusiveness, in particular the Universidad Complutense de Madrid (E MADRID03) and the University of Granada (E GRANADA01). These two institutions outperformed the country average level of inclusiveness at 
the beginning of the period but fell behind it at the end. Third, a group of universities improves its level of inclusiveness, in particular the Freie Universität Berlin, the Universidad Autonoma de Barcelona (E BARCELO01), and the Universität Wien (A WIEN01) initially show a negative value of the index but eventually outperform their country average.

A further change observable over time is that values are initially more heterogeneous, while at the end of the period they tend to concentrate in two groups: universities outperforming their respective national average level of inclusiveness, and universities that are less inclusive than the country they belong to. The former group includes for instance the University of Oslo and the Rijksuniversiteit Groningen, whereas a group of Spanish universities, e.g. the University of Valencia and the Polytechnic University of Valencia, belongs to the latter.

Two channels can be identified as instruments for universities to become more inclusive. The first is to acquire more partnerships with other universities since more links would guarantee more incoming students. The second is to link with equally inclusive universities that would guarantee a consistent flow of students with disabilities. In the network analyzed, the first channel seems highly predominant since student flows mostly consist of only one student (recall previous section and Table 2). Among the 13 universities identified as the most inclusive, four appear among the top- 5 receiving HE institutions in 2008 displayed in Table 3: the University of Granada (E GRANADA01), the Charles University in Prague (CZ PRAHA07), the University of Valencia (E VALENCI01), the Universidad Complutense de Madrid (E MADRID03); while two of them are among the top-5 receivers in 2013: the Universidad Autonoma de Barcelona (E BARCELO01), and the Freie Universität Berlin (D BERLIN01). The four inclusive universities and top receivers in 2008 see a decrease in their level of inclusiveness (Fig. 5) that follows the decrease in the number of links so that they no longer appear among the top-5 receivers in 2013 (Table 2). Vice versa for the two inclusive universities present among the top-5 receivers in 2013: the Universidad Autonoma de Barcelona (E BARCELO01) and the Freie Universität Berlin (D BERLIN01) increase their level of inclusiveness as highlighted by the green lines in Fig. 5 as they grow their indegree (Table 3).

This first channel seems to operate better in 2008 and worse in 2013, when the number of inclusive universities, according to our definition, decreases among the top- 5 receivers. Conversely, the second channel performs better in 2013: the 13 inclusive universities have no links between them (consistently with the observed distinction between senders and receivers), with the exception of the Universidad Autonoma de Barcelona (E BARCELO01) and the University of Rome La Sapienza (I ROMA01) in 2008. The links become two in 2013 as the Universität Wien (A WIEN01) is connected to the Charles University in Prague (CZ PRAHA07), and the University of Ljubljana (SI LJUBLJA01) is linked to the Universidad Autonoma de Barcelona (E BARCELO01). This seems consistent with the slight increase in assortativity from 2008 to 2013 observed in Table 2.

This may signal a tendency of HE institutions towards increasing partnerships with inclusive universities to ensure a higher level of inclusiveness, rather than multiplying agreements between universities. The distinction between sending and receiving universities could become less sharp and be replaced by a distinction between inclusive and non-inclusive universities. 
However, this interpretation remains limited to the discussion on the very small number of universities defined as inclusive, and speculative in nature as, in almost all cases, flows consist of only one student and no increase in the flow capacity has been observed. In addition, data do not allow to observe agreements in place among universities when no student exchange happens at a given time. Thus, links remain a weak indication of international agreements.

\section{Concluding remarks}

The Erasmus Program has been characterized by a low level of participation by students with special needs. Combining different data sources we quantified this evidence and explored the level of inclusiveness and the network of universities contributing to the mobility of students with disabilities.

The main results of the study can be summarized as follows:

- The data collection highlighted a problem of availability and reliability of data on students with special needs in HE in European countries. On the one hand, reasons can be searched in the sensitive nature of data and their self-disclosure requirement; on the other hand, the collection of this information at country level appears still disorganized and in its early stages.

- Participation in Erasmus by students with disabilities is extremely low with respect to the total number of Erasmus students and to the number of students with disabilities enrolled in HE in Europe. However, the share of Erasmus students with disabilities has doubled over the period 2008-2013.

- In almost every participating country in 2013, a higher share of female than male students in HE took part in the mobility. The network of universities involved in the mobility of students with special needs shows a gender bias in favor of female connections which has been increasing along the period 2008-2013, contrary to the mild tendency towards a reduction of the bias observed in previous research for the network of disabled and non-disabled students.

- Mobility in the STEM fields has been diminishing over 2008-2013 for both male and female students with disabilities.

- Universities involved in the mobility of students with special needs tend to polarize in the role of sender or receiver, following a well defined geographical trajectory: universities from the South-West North-East European axis, i.e. those located in Spain, France, UK, the Netherlands, and Scandinavian countries, are receiving universities, whereas institutions located in Italy, Germany and Eastern countries are sending universities. The exception is represented by universities located in capital cities, which tend to be both sender and receivers.

- In the 6-year period between 2008 and 2013 only 13 universities continuously welcomed Erasmus students with disabilities each year. Universities such as the Rijksuniversiteit Groningen and the University of Oslo are among the most inclusive, outperforming their respective national average of incoming students with special needs. The University of Valencia and the Polytechnic University of Valencia are instead among those furthest from reaching the national average. We observed a mild tendency of inclusive universities towards higher assortativity, thus creating 
partnerships with equally inclusive universities, rather than increasing the number of links, in order to ensure a higher level of inclusiveness.

This work represents the first attempt to measure the participation of students with disabilities to Erasmus. This could lead further research to a new research stream and constitute a quantitative basis supporting and helping policymakers design appropriate policies aiming at better inclusiveness. Evidence from this work may be relevant for at least three different types of stakeholders. First, EU institutions could better define Erasmus priorities and, knowing the dimension of this phenomenon, take targeted action to increase the participation of students with disabilities in the program. Second, universities in Europe could exploit this evidence to define their own inclusiveness policy which could ensure and increase the welcoming of students with health conditions. Finally, students could benefit from information about the level of inclusiveness of universities and countries by taking more informed decisions about their study mobility.

The main limitation of this study consists in the availability and reliability of data, which affects the robustness of our findings. Approximations have been used to study an aspect that would require much greater attention. For this reason, we encourage the European HE institutions to start a systematic collection of information on the participation to education by students with special needs. Quantifying the phenomenon can be a key strategy to widen their participation in HE and international mobility. Although low, the participation to Erasmus by students with special needs has been growing and it will probably continue to follow this trend in the future, considering the greater budget dedicated to the next seven years of the program. For this reason, further research could explore and follow future developments of the program and future participation of students with special needs. It could be relevant then to further explore its time dimension. As new data become available, future research could analyze a longer time span and investigate possible similarities or differences across the period, for example through the use of a dynamic network approach (Batagelj et al. 2014). In addition, the switch to Erasmus + in 2014 has substantially changed the availability of funds. A quasi-experimental design, in which the participation to Erasmus + determines the treatment, could investigate whether Erasmus + affected the participation of students with special needs.

Future research could also depart from two recent events that affected higher education in Europe. The first one is Brexit and the following exit of the UK from the Erasmus program. Evidence from this work showed that the UK has a relevant role as a receiver of international students with disabilities. Moreover, in 2021 the UK is starting the Turing scheme, its own global program to study and work abroad. New research questions could explore how this may affect the participation of students with special needs and the probability for them to undertake the mobility in different universities or renounce to the international experience. How will participation in the Turing scheme differ from participation to Erasmus? A specific line of research could be addressed to students with special needs participating in this program. Will they meet the same barriers and benefits to mobility as students in the EU participating to Erasmus? Will the Turing scheme guarantee higher or lower inclusiveness with respect to Erasmus? When enough information on the newborn scheme will be available, a comparison between the two programs could reply to these questions. The second event is the ongoing pandemics. This bears short-term effects on the 
program which saw many European universities closing and their courses partly or entirely moved online, and long-term effects as online teaching becomes integrated with the educational offer provided by universities. Will this produce changes in the flows of Erasmus students? Will the participation of students with disabilities be affected? We assume that the health crisis may constitute a bigger obstacle for students with health conditions.

A further extension to this work may be represented by the definition of a more comprehensive index of inclusiveness which includes every university taking part in the program and which could help define an international ranking to be available to all actors of higher education and especially students making decisions about their mobility abroad.

Finally, evidence from this work leaves doubts about the reasons why more female than male students with impairments take part in the Erasmus mobility. Sociological and psychological literature could try to answer these questions by studying possible differences in the attitude towards autonomy and initiative, as well as in social skills and network of friendships formation.

\section{Abbreviations}

ADHD: Attention deficit hyperactivity disorder; ERASMUS: EuRopean community Action Scheme for the Mobility of University Students; EU: European Union; HE: Higher education; ICTs: Information and communication technologies; ISCED: International Standard Classification of Education; LDs: Learning disabilities; SNA: Social network analysis; STEM: Science, technology, engineering and mathematics.

\section{Acknowledgements}

We are thankful to the Editor of the journal, Hocine Cherifi, and the anonymous referees who provided insightful comments and suggestions on a preliminary version of this work. We are also grateful to the organizers and participants of the session "Erasmus mobility flows and project cooperation in Network Perspectives" at the 5th European Conference on Social Networks, EUSN2021.

\section{Authors' contributions}

Both authors planned the research project. Silvia Leoni collected and prepared the original data, and wrote the manuscript. Luca De Benedictis coded the network analysis in R and provided the network visualization (Figs. 3 and 4). Both authors contributed to the empirical analysis, while Silvia Leoni worked on the visualization of Figs. 1,2 and 5. Both authors read and approved the final manuscript.

\section{Funding}

The research reported was conducted with no funding.

\section{Availability of data and materials}

The original datasets used during the current study are available at the following repositories:

- EU open data portal (https://data.europa.eu/en)

- Eurostudent (http://database.eurostudent.eu/)

- Eurostat (https://ec.europa.eu/eurostat/web/education-and-training/data/database)

- Higher Education Statistics Agency (https://www.hesa.ac.uk/data-and-analysis/students/table-15)

- The datasets and $\mathrm{R}$ scripts coded by the authors are available upon request for replication purposes.

\section{Declarations}

Competing interests

The authors declare that they have no competing interests.

\section{Author details}

${ }^{1}$ Department of Economics and Law, University of Macerata, Via Crescimbeni 14, 62100 Macerata, Italy. ${ }^{2}$ Department of Business and Management, Luiss, Viale Romania 32, 00197 Rome, Italy. ${ }^{3}$ School of Business, University of Leicester, London Road 266, Leicester LE2 1RQ, UK.

Received: 10 June 2021 Accepted: 20 September 2021

Published online: 02 November 2021

\section{References}

Batagelj V, Doreian P, Ferligoj A, Kejzar N (2014) Understanding large temporal networks and spatial networks: exploration, pattern searching, visualization and network evolution, vol 2. Wiley, London 
Behrnd V, Porzelt S (2012) Intercultural competence and training outcomes of students with experiences abroad. Int $J$ Intercult Relat 36(2):213-223

Bottcher L, Araujo NA, Nagler J, Mendes JF, Helbing D, Herrmann HJ (2016) Gender gap in the ERASMUS mobility program. PLOS ONE 11(2):e0149514

Bound J, Brown C, Mathiowetz N (2001) Measurement error in survey data, vol 5. Handbook of econometrics. Elsevier, Amsterdam, pp 3705-3843

Braskamp LA, Braskamp DC, Merrill K (2009) Assessing progress in global learning and development of students with education abroad experiences. Front Interdiscip J Study Abroad 18:101-118

Breznik K (2017) Institutional network of engineering students in the Erasmus programme. Glob J Eng Educ 19(1):36-41

Breznik K, Djaković G (2016) Erasmus student mobility flows-the national-level social network analysis of Slovenia. Int J Innov Learn 20(2):124-137

Breznik K, Ragozini G ( 2015) Exploring the Italian Erasmus agreements by a network analysis perspective. In: Proceedings of the 2015 IEEE/ACM international conference on advances in social networks analysis and mining, pp 837- 838

Breznik K, Skrbinjek V (2020) Erasmus student mobility flows. Eur J Educ 55(1):105-117

Bryła P (2015) The impact of international student mobility on subsequent employment and professional career: A large-scale survey among Polish former Erasmus students. Procedia Soc Behav Sci 176:633-641

De Benedictis L, Leoni S (2020) Gender bias in the Erasmus network of universities. Appl Netw Sci 5(1):1-25

de Boer A, Pijl SJ, Post W, Minnaert A (2013) Peer acceptance and friendships of students with disabilities in general education: the role of child, peer, and classroom variables. Soc Dev 22(4):831-844

Derzsi A, Derzsy N, Káptalan E, Néda Z (2011) Topology of the Erasmus student mobility network. Physica A 390(13):2601-2610

Doyle S, Gendall P, Meyer LH, Hoek J, Tait C, McKenzie L, Loorparg A (2010) An investigation of factors associated with student participation in study abroad. J Stud Int Educ 14(5):471-490

du Toit NH (2018) Designing a model for facilitating the inclusion of higher education international students with disabilities in South Africa. Soc Inclus 6(4):168-181

d'Hombres B, Schnepf SV (2021) International mobility of students in Italy and the UK: does it pay off and for whom? High Educ. https://doi.org/10.1007/s10734-020-00631-1

Engel C (2010) The impact of Erasmus mobility on the professional career: empirical results of international studies on temporary student and teaching staff mobility. Belgeo. Revue belge de géographie 4:351-363

European Commission (2015) Erasmus+ Programme: Annual Report 2014. Publications Office of the European Union Luxembourg)

European Commission (2021). https://ec.europa.eu/commission/presscorner/detail/en/ip_21_1326. Accessed 22 Apr 2021

European Parliament and Council of European Union (2013) Regulation (EU) No 1288/2013. https://eur-lex.europa. eu/legal-content/EN/TXT/PDF/?uri=CELEX:32013R1288\&from=EN

Eurostat (2016) Disability statistics—prevalence and demographics. https://ec.europa.eu/eurostat/statistics-expla ined/pdfscache/34409.pdf

Eurostat (2018) Disability statistics - access to education and training. https://ec.europa.eu/eurostat/statistics-expla ined/pdfscache/34423.pdf

Farmer TW, Van Acker RM, Pearl R, Rodkin PC (1999) Social networks and peer-assessed problem behavior in elementary classrooms: students with and without disabilities. Remed Spec Educ 20(4):244-256

Hameister B, Mathews P, Hosley N, Groff MC (1999) College students with disabilities and study abroad: Implications for international education staff. Front Interdiscipl J Study Abroad 5(2):81-100

Heirweg S, Carette L, Ascari A, Van Hove G (2020) Study abroad programmes for all? Barriers to participation in international mobility programmes perceived by students with disabilities. Int J Disabil Dev Educ 67(1):73-91

Johnstone C, Edwards P (2020) Accommodations, accessibility, and culture: increasing access to study abroad for students with disabilities. J Stud Int Educ 24(4):424-439

Keogh J, Russel-Roberts E (2009) Exchange programmes and student mobility: meeting student's expectations or an expensive holiday? Nurse Educ Today 29(1):108-116

Kitsantas A (2004) Studying abroad: the role of college students' goals on the development of cross-cultural skills and global understanding. Coll Stud J 38(3):441

Kleinberg JM (1999) Authoritative sources in a hyperlinked environment. J ACM 46:604-632

Langley CS, Breese JR (2005) Interacting sojourners: a study of students studying abroad. Soc Sci J 42(2):313-321

Maiworm F (2001) ERASMUS: continuity and change in the 1990s. Eur J Educ 36(4):459-472

Mamas C, Schaelli GH, Daly AJ, Navarro HR, Trisokka L (2020a) Employing social network analysis to examine the social participation of students identified as having special educational needs and disabilities. Int J Disabil Dev Educ 67(4):393-408

Mamas C, Bjorklund P Jr, Daly AJ, Moukarzel S (2020b) Friendship and support networks among students with disabilities in middle school. Int J Educ Res 103:101608

Oborune K (2013) Becoming more European after Erasmus? The impact of the Erasmus programme on political and cultural identity. Epiphany 6(1):182-202

Otero MS, McCoshan A (2006) Survey of the socio-economic background of ERASMUS students-DG EAC 01/05. Final report

Papatsiba V (2005) Political and individual rationales of student mobility: a case-study of ERASMUS and a French regional scheme for studies abroad. Eur J Educ 40(2):173-188

Parey M, Waldinger F (2010) Studying abroad and the effect on international labour market mobility: evidence from the introduction of ERASMUS. Econ J 121(551):194-222

Restaino M, Vitale MP, Primerano I (2020) Analysing international student mobility flows in higher education: a comparative study on European countries. Soc Indic Res 149:947-965 
Shames W, Alden P (2005) The impact of short term study abroad on the identity development of college students with learning disabilities and/or AD/HD. Front Interdiscip J Study Abroad 11(1):1-31

Shields R (2013) Globalization and international student mobility: a network analysis. Comp Educ Rev 57(4):609-636

Souto-Otero M, Huisman J, Beerkens M, De Wit H, Vujić S (2013) Barriers to international student mobility: evidence from the Erasmus program. Educ Res 42(2):70-77

Teichler U, Jahr V (2001) Mobility during the course of study and after graduation. Eur J Educ 36(4):443-458

Wasserman S, Faust K (1994) Social network analysis: methods and applications. Cambridge University Press, Cambridge

\section{Publisher's Note}

Springer Nature remains neutral with regard to jurisdictional claims in published maps and institutional affiliations.

Submit your manuscript to a SpringerOpen ${ }^{\circ}$ journal and benefit from:

- Convenient online submission

- Rigorous peer review

- Open access: articles freely available online

- High visibility within the field

- Retaining the copyright to your article

Submit your next manuscript at $\boldsymbol{\Delta}$ springeropen.com 